\title{
Energy Audit and Management of a Tannery Company: A Case Study of Kano State
}

\author{
Jamilu Ya'u Muhammad, ", Sirajo Alhassan", Ibrahim Sule Ahmad Abdulmajeed ${ }^{2}$, \\ Nuhu Hassan Waziri ${ }^{3}$, Najib Aminu Ismail ${ }^{4}$, Faru Faruk Tukur ${ }^{4}$ \\ ${ }^{1}$ Department of Mechanical Engineering, Bayero University, Kano, Nigeria \\ ${ }^{2}$ Department of Mechanical Engineering, Federal Airports Authority of Nigeria, Abuja, Nigeria \\ ${ }^{3}$ Department of Mechanical Engineering, Modibbo Adama University of Technology, Yola, Nigeria \\ ${ }^{4}$ Department of Mechanical Engineering, Ahmadu Bello University, Zaria, Nigeria
}

\section{Email address:}

jambcyfm $@$ yahoo.com (J. Y. Muhammad)

${ }^{*}$ Corresponding author

\section{To cite this article:}

Jamilu Ya'u Muhammad, Sirajo Alhassan, Ibrahim Sule Ahmad Abdulmajeed, Nuhu Hassan Waziri, Najib Aminu Ismail, Faru Faruk Tukur. Energy Audit and Management of a Tannery Company: A Case Study of Kano State. American Journal of Electrical Power and Energy Systems. Vol. 9, No. 1, 2020, pp. 1-13. doi: 10.11648/j.epes.20200901.11

Received: November 16, 2019; Accepted: February 26, 2020; Published: March 23, 2020

\begin{abstract}
Energy audit is considered as one of the comprehensive methods in checking the energy usage and wastage in facilities/buildings. This paper presents the results of the energy audit conducted to investigate the energy consumption pattern of tannery company from its record of fuel expenditure and electricity bills for a period of 5 years (2012 - 2016). Also, the use of energy models system, Energy Quick Energy Simulation Tool (eQUEST) to evaluate the consumption of the energy end users and performance of the company. Results shows peak electricity demand during the hot months from April to August due to high cooling or significant Air condition requirement. $2.37 \%$ of electricity consumed was contributed by the burning of AGO in the diesel power generators showing very less contribution over that of National grid $97.63 \%$. The annual average consumption demand of electricity and diesel (kWh equivalent) of the company were $118960.72 \mathrm{kWh}$ and $2881.17 \mathrm{kWh}$ respectively. The energy modeling and simulation results shows that the sum total of the total monthly energy consumption by the end users is $138164 \mathrm{kWh}$ representing the total average value of the annual energy use in air-conditioning (space cooling) was $27 \%$, ventilation fan $2 \%$, factory machineries $39 \%$, heat rejection is $4 \%$, pump and auxiliary is $2 \%$ and area lighting $26 \%$. Also, the total monthly peak demand by space cooling was $22372.2 \mathrm{kWh}$, ventilation fan $1376 \mathrm{kWh}$, factory machineries $14294 \mathrm{kWh}$ heat rejection is $4461 \mathrm{kWh}$, pump and auxiliary is $1343 \mathrm{kWh}$ and area light $11023 \mathrm{kWh}$ respectively having a sum total monthly peak demand by the end users to be $44969.2 \mathrm{kWh}$. This represent energy use in air-conditioning (space cooling) was $41 \%$, ventilation fan $3 \%, 26 \%$ factory machineries, heat rejection is $8 \%$, pump and auxiliary is $2 \%$ and $20 \%$ area light of the annual peak demand. The Energy Used Index (average annual electricity use per tones of leather) was found to be $717.38 \mathrm{kWh} /$ tones of leather/Annum.
\end{abstract}

Keywords: Energy Audit, National Grid, eQUEST, Leather, AGO

\section{Introduction}

Energy has a major impact on every aspect of our socioeconomic life. It plays a vital role in the economic, social and political development of our nation. Inadequate supply of energy restricts socio-economic activities, limits economic growth and adversely affects the quality of life [1]. In Nigeria, a lot of energy is wasted because households, public and private offices, as well as industries use more energy than is actually necessary to fulfill their needs. One of the reasons is that they use outdated and inefficient equipment and production processes, therefore, the need for energy is exceeding it is supply in view of these circumstances, primary energy conservation, 
rationalization, and efficient use are immediate needs. Getting all the possible energy from the fuel into the working fluid is the goal of efficient equipment operations. This leads to higher productivity and saves not only money, but also influences the life and safety of the equipment and reduces pollution [2].

Global, country-specific, and industry-specific analyses continue to show that significant energy-efficiency improvement opportunities exist in the industrial sector, many of which are cost-effective. These energy-efficiency options include both cross-cutting as well as sector-specific measures. However, industrial facilities are not always aware of their overall energy efficiency improvement potential or specific technologies and measures that can be implemented. One of the most common methods adopted around the world to address these issues is to undertake an industrial energy audit. An industrial energy audit is a necessary first step for defining energy consumption by end use and identifying key areas for energy saving in industrial operations. Without baseline energy use data, it is impossible to have a clear understanding of the current situation or to make cost-effective decisions regarding energy-efficiency strategies. An industrial energy audit is also an important impetus to encourage industrial facilities to implement energy-efficiency measures and technologies with most saving potential. In general, preliminary energy audits provide quick estimates of costs, potential cost and energy savings, as well as simple payback periods. Comprehensive energy audits, on the other hand, are enabled to provide detailed cost-effective analysis of all identified measures and technologies, based on plant's specific operating conditions. Creditable energy audits provide packages of customized recommendations for plants to consider. In this regard, an energy audit is often a key component of industrial energy efficiency programs and has also been considered as a supporting policy tool for policies such as voluntary agreements or emissions cap and trade policies [3].

Energy audits are an inspection of energy consumption habits within a building. An audit team examines utility bills, lights, plug loads, the HVAC system, and the building envelope to gather data. These data are used to create one or more models of energy consumption in the building. After these models are verified against actual building consumption, potential methods to reduce energy consumption are modeled to quantify savings from the implementation of each method. Once savings for an Energy Conservation Measure (ECM) are quantified, a financial analysis is performed to determine whether that measure is worth implementing. The worthwhile ECMs are recommended to building owners; along with details about the financial and material investment each measure requires [4].

From the literature, many studies related energy efficiency and savings based on the building sector like commercial and high-volume buildings have found $[5,6]$.

\section{Materials and Method}

\subsection{Materials}

Materials used in this research are as follows:

a) Electricity bills file.

b) AGO consumption file.

c) Records of skin processed.

d) Power ratings of factory machineries.

e) eQUEST 3-6.5 version Energy simulation software.

f) Laptop Computer.

\subsubsection{Energy Audit Simulator}

Computer-based simulation is accepted by many energy efficiency studies as a reliable tool for evaluating building energy use and retrofit possibilities [7-9]. eQUEST was decided to use because it is a user friendly freeware program that offers a comprehensive set of features: eQUEST predicts the hourly energy use and energy cost of a building given user-input information including hourly weather data, building layout, HVAC description, and utility rate structure [10].

eQUEST v3.65 was used in creating a simulation model of the case study building based on building schematic drawings. In addition to building parameters weather data was also required. The closest weather station with complete weather data available for the period under consideration is in Kano, Nigeria. Utility bills for diesel and electricity from January 2012 and December 2016 were compiled for comparison against simulated energy consumption.

\subsubsection{Factory Machineries and Their Uses}

The following are some factory machineries descriptions and their uses:

a) De-dusting Machine: This is a metal mesh rotating cylinder that can provide the de-dusting process suitable to remove dust from double face leather.

b) Dry Buffing Machine: This is a cylinder machines, equipped with sandpaper or emery for the processing of leather with unbuckle or suede effect, or to correct any defects on the leather grain side. Control devices with hydraulic drive are used to quickly reverse the direction of rotation of the feed roller and make it easier the manual extraction of the leather. The systems are supplemented by specific elements of the dust extraction and collection in the bags.

c) Fleshing Machine: This is a machine which is scraping off of the excessive organic material from the hide (connective tissue, fat and so on).

d) Shaving Machine: This is used in carrying out of shaving process in order to achieve an even thickness throughout the skin/hide, and it can be carried out on tanned or crusted leather.

e) Drying machines: The objective of drying is to dry the leather whilst optimizing the quality and area yield. Drying techniques include samming, centrifuging, setting, hang drying, vacuum drying, toggle drying and paste drying. 
Table B8 present the power rating and estimated daily and monthly energy consumptions of factory machineries and other equipment used in the company.

\subsubsection{Computer Laptop Specifications}

HP pavilion g6 computer core "i5 system, $2.50 \mathrm{GHz}$ processor, 8GB RAM size on Microsoft window 7 operating system is used in the research simulation.

\subsection{Method}

\subsubsection{Data Collection}

For the energy carriers, the first stage in this study was the data collection, in which a meeting was held with the Management and all key operating personnel, and they were briefed over the audit objectives, the scope of the work and description of scheduled project activities. An energy audit check list was drawn to acquire data by physical checks. The monthly consumption figures of two energy carriers (Electrical and AGO) for a period of five years (2012 - 2016) were extracted from electrical consumption and diesel consumption files from physical personnel of the company. Also, information obtained by physical checks where used to construct various types of electricity used profiles, comparison tables, corresponding correlation plots.

\subsubsection{Data Analysis}

From the data collected, the following procedural steps were adopted to analyze the data, inputted and presented in the required forms:

a) Data Analysis for Energy carries

i. Energy types (electricity and AGO) were identified and collated.

ii. The energy consumption per year for each type of energy carrier was determined.

iii. The percentage breakdown of total energy consumption was calculated.

iv. The energy used index (EUI) in $(\mathrm{kWh} /$ tones of leather/per) year was determined to establish energy utilization pattern.

b) Computations for Electrical Energy consumption (kWh) and percentage $(\%)$ share for types.

i. Energy carriers (National grid and AGO)

In this study, monthly average electrical energy consumption and percentage share for the period of 5 years (i.e. 2012 to 2016) are computed from the relation given as follows [3]:

$$
\begin{gathered}
A M E E C=\frac{1}{5}\left[\sum_{i=1}^{5}(M E E C)\right]_{K} \\
(M A A E E C)_{k}=\frac{1}{12}\left[\sum_{i=1}^{12}(T E E C)\right]_{K} \\
\text { Monthly Percentage Share }(\%)=\frac{M E E C}{T E E C} \times 100 \\
X_{T}=X_{\text {grid }}+X_{\text {gen }}
\end{gathered}
$$

Where:

AMEEC: Average monthly electrical energy consumed from 2012 to 2016
MAAEEC: Monthly annual average electrical energy consumption

TEEC: The total electrical energy consumed per annum

k: The year i.e 2012, 2013, 2014, 2015 and 2016

MEEC: Monthly electrical energy consumed

AEEC: Annual electrical energy consumed

$\mathrm{X}_{\mathrm{T}}$ : Monthly total of energy consumption of national grid and $\mathrm{AGO}$

$\mathrm{X}_{\text {grid: }}$ Monthly energy consumption from national grid

$\mathrm{X}_{\text {gen }}$ : Monthly energy consumption from AGO

The Automotive Gas Oil (AGO) consumed in MJ was converted to $\mathrm{kWh}$ for data analysis. And the equivalent energy value of $3.6 \mathrm{MJ}=1 \mathrm{kWh}$.

For example the monthly electricity consumption from combined energy types for each month was $\mathrm{X}_{\mathrm{T}}=\mathrm{X}_{\text {grid }}+$ $\mathrm{X}_{\text {gen }}$

For the month of January 2012

$$
\begin{gathered}
\mathrm{X}_{2012_{\mathrm{Jan}}}=X_{\text {grid }_{\text {Jan }}}+X_{\text {gen }_{\text {Jan }}}=38019 \mathrm{MJ}+774 \mathrm{MJ} \\
=38793 \mathrm{MJ}=10775.83 \mathrm{kWh}
\end{gathered}
$$

Values for the subsequent month and years were computed and presented in the Appendix "B" table B1.

AMEEC for electricity consumption from combine energy types for the month of January was computed using equation (1) above

$$
\begin{aligned}
&(A M E E C)_{\text {january }}=\frac{1}{5}\left(M E E C_{2012}+M E E C_{2013}\right. \\
&+\left.M E E C_{2014}+M E E C_{2015}+M E E C_{2016}\right) \\
&(A M E E C)_{\text {january }}=\frac{1}{5}(10775.83 k W h+9015.56 k W h \\
&+10100 k W h+10334.72 k W h \\
&+10148.33 k W h)=10074.89 k W h
\end{aligned}
$$

Values for the subsequent months were computed and presented in table B1 of Appendix "B".

MAAEEC for electricity consumption from combine energy types for the year 2012 was computed using equation 2:

$$
\begin{gathered}
(M A A E E C)_{k}=\left[\sum_{i=1}^{12}(T E E C)\right]_{K} \\
M A A E E C=123945.3 \mathrm{kWh}
\end{gathered}
$$

Values for the subsequent months were computed and presented in table B2 of Appendix "B".

Also yearly percentage of energy types can be deduced using equation (3) above. For the year 2012 we have,

$$
\begin{gathered}
\text { year }(\%)_{\text {natural grid }}=\frac{120907.5}{123945.2778} \times 100=97.5 \% \\
\text { year }(\%)_{A G O}=\frac{3037.778}{123945.2778} \times 100=2.5 \%
\end{gathered}
$$

Values for the subsequent months were computed and 
presented in table B3 of Appendix "B".

ii. National Grid

In this research, monthly electricity consumption and annual total for period of 5 years (2012-2016) were obtained using equations given above:

AMEEC for national grid consumption for the month of January can be found using equation 1 :

$$
\begin{aligned}
(A M E E C)_{\text {january }} & =\frac{1}{5}\left(M E E C_{2012}+M E E C_{2013}+M E E C_{2014}+M E E C_{2015}+M E E C_{2016}\right) \\
& =\frac{1}{5}(38019+31708+35672+36455+35707) M J \\
& =\frac{1}{5}(177561 M J)=9864.5 \mathrm{kWh}
\end{aligned}
$$

Values for the subsequent months were computed and presented in table B9 of Appendix "B".

MAAEEC for national grid consumption for the year 2012 was computed using equation 2:

$$
\begin{gathered}
(\text { MAAEEC })_{k}=\left[\sum_{i=1}^{12}(\text { TEEC })\right]_{K} \\
M A A E E C=(38019+36825+34972+36075+37280+35555+37331+32963+38467+36035+35929 \\
+35816) M J=435267 M J=12090.55 \mathrm{kWh}
\end{gathered}
$$

Values for the subsequent years were computed and presented in table B2 of Appendix "B".

MAAEEC for year 2012 is computed using equation:

$$
(M A A E E C)_{2012}=\frac{12090.55}{12}=1007.55 \mathrm{kWh}
$$

Values for the subsequent years were computed and presented in table B4 of Appendix "B".

iii. Automotive gas oil (AGO)

In this study, AGO consumption by company generator was analyzed. The average monthly diesel consumption, monthly Annual Average diesel consumption and Annual total were determined using the relation as follows [4]:

$$
\begin{gathered}
(M A D C)_{k}=\frac{1}{5}\left(\sum_{i=1}^{5} T D C\right) \\
(A M D C)_{k}=\frac{1}{12}\left(\sum_{i=1}^{12} T D C\right)
\end{gathered}
$$

Where:

$k$ : The year

AMDC: Average monthly diesel consumption

MADC: Monthly Annual average diesel consumption

$i$ : The number of month,

TDC: Total diesel consumed per annum

MADC for the year 2012 was computed using equation 5:

$$
(M A D C)_{2012}=\frac{10936 M J}{12}=911.33 M J=23.61 \text { litres }
$$

The values of the average consumption for the subsequent years were computed and presented in table B5 of the Appendix "B"

The total annual consumption in terms of kWh for years (2012-2016) were computed and presented in table B2.

Overall percentage contribution of each source

$$
\begin{gathered}
\text { National grid contribution }=594803.61 \\
\text { Diesel }(\text { AGO) contribution }=14405.83 \\
\text { Total }=609209.44 \\
\text { Percentage of national grid }=\frac{594803.61}{609209.44} \times 100=97.6 \% \\
\text { Percentage AGO }=\frac{14405.83}{609209.44} \times 100=2.4 \%
\end{gathered}
$$

The results were computed and presented in table B3 Appendix "B". The annual percentage contribution of each source is computed and presented in table B3 appendix B.

c) Evaluation of Energy Used Index (Annual electricity Used per tones of leather)
A total of five years $(2012-2016)$ electricity consumption data was collected and analyze. To simplify the analysis, the consumption data was averaged over five year's period. Energy used per tones of leather (also known as energy utilization index) is used to compare the energy intensity 
among different years.

Sample calculation of energy used index for the year 2012.

$$
\begin{array}{r}
\text { Energy Used Ind } \\
E U I=\frac{123945.28}{174} \\
E U I=712.33 \frac{\mathrm{kWh}}{\text { tones of leather }} / \text { year }
\end{array}
$$

Values for the subsequent years were computed and presented in table B6 of Appendix "B".

\subsubsection{Computer Simulation}

\section{A. Building Description}

The case building selected for this research is an industrial building located in the challawa industrial building area of Kano, Nigeria. It is cumulative building area is $51224 \mathrm{~m}^{2}$ and comprises of machineries area of $41282 \mathrm{~m}^{2}$ and $9942 \mathrm{~m}^{2}$ for administration area.

B. Building Material and Envelope

The exterior walls of the building are 9 inches blocks with R-12 polystyrene insulation. The floor is 6 inches concrete base with ceramic/stone finish. The internal walls are 6 inches sheetrock framed on metal studs with insulation on select interiors. The building is operated under positive pressure, which eliminates any potential envelope infiltration. A screenshot of the eQUEST wizard screen for inputting building material and envelope details is displayed in figure C1.

C. Heating Ventilation and Air conditioning (HVAC)
System

The building air conditioning is primarily a standard VAV and the domestic hot water is provided by a domestic hot water supply loop connected to central hot water pumps (figure $\mathrm{C} 2$ ).

D. Building Schedules

The building is in operation 5 days a week from Monday through Friday. The occupants generally begin to enter at around $7 \mathrm{am}$ and leave at $5 \mathrm{pm}$. The building is closed on Saturday and Sunday as well as on local holidays. A typical schedule input screen for eQUEST is shown in figure C3.

\section{Results and Discussions}

\subsection{Results}

\subsubsection{Energy Carriers}

Figures 1 and 2 present the monthly electricity $(\mathrm{kWh})$ consumptions pattern and annual energy consumed by energy carriers (electricity and diesel) consumption pattern. These graphs were obtained using Tables B1 and B2 (Appendix B) respectively.

Figures 3 present the monthly diesel $(\mathrm{kWh})$ consumptions pattern. This graph was obtained using Table B7.

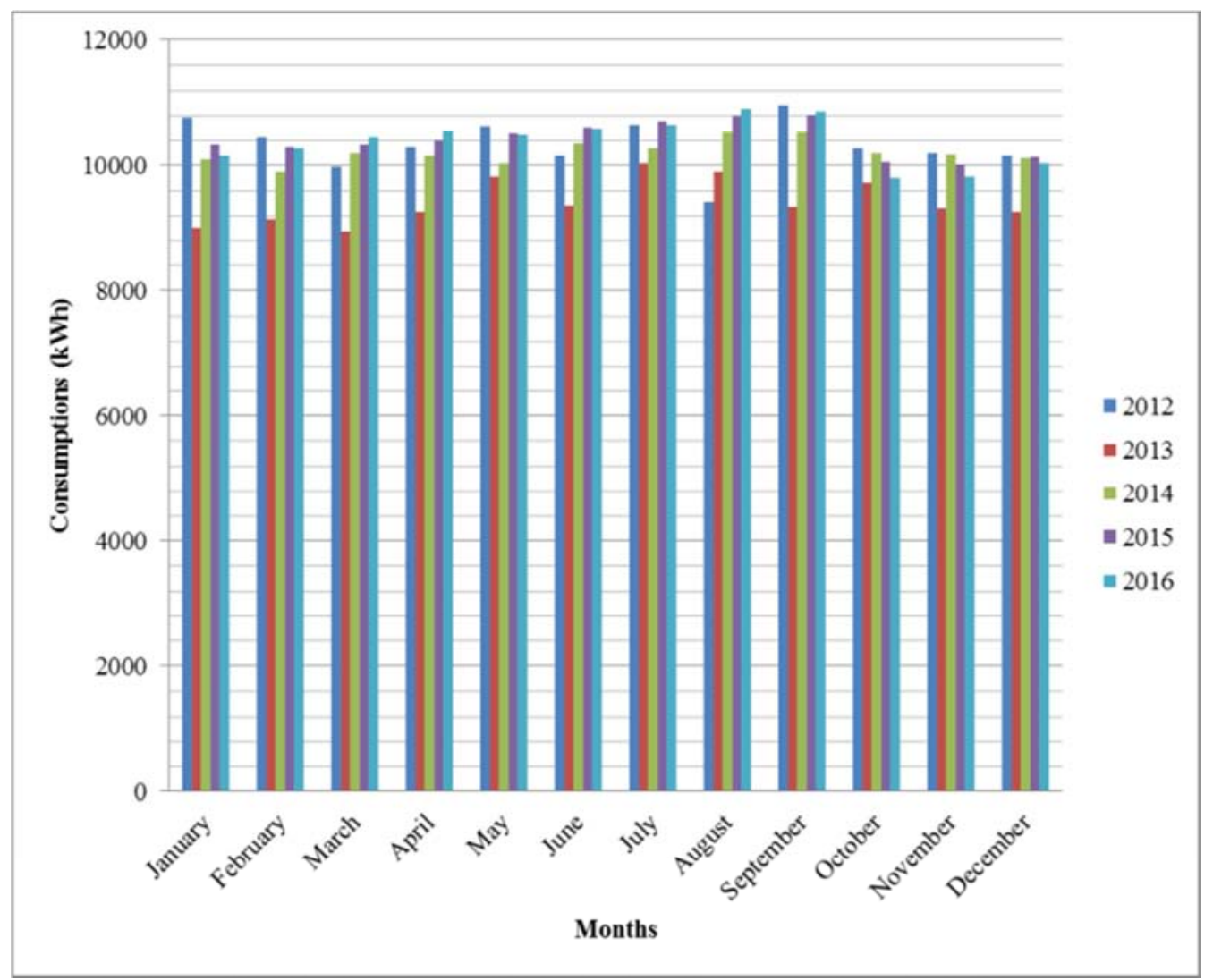

Figure 1. Monthly Electricity Energy Consumption Pattern (2012 - 2016). 


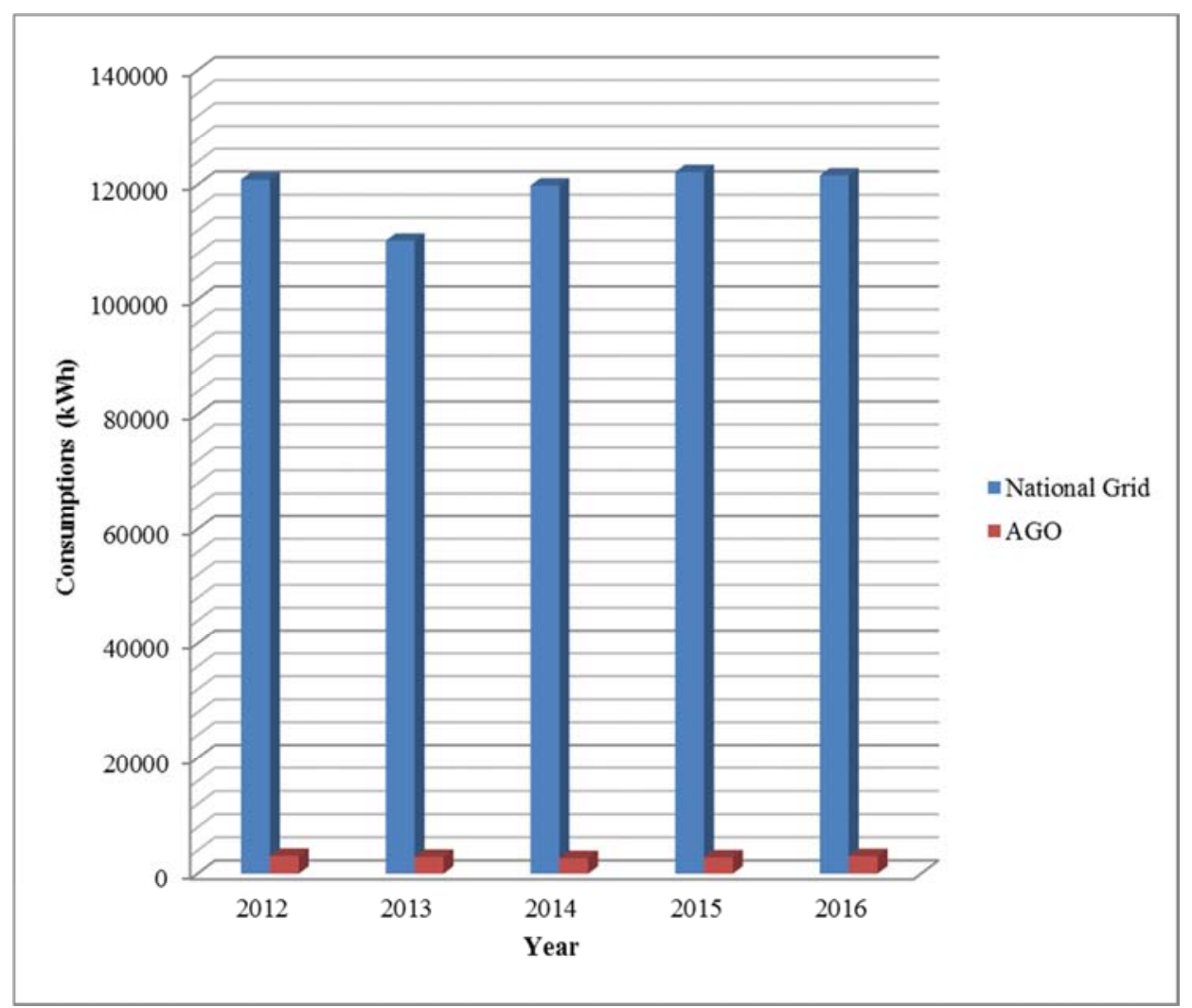

Figure 2. Energy Consumed by Energy carriers (National Grid and AGO) (2012 - 2016).

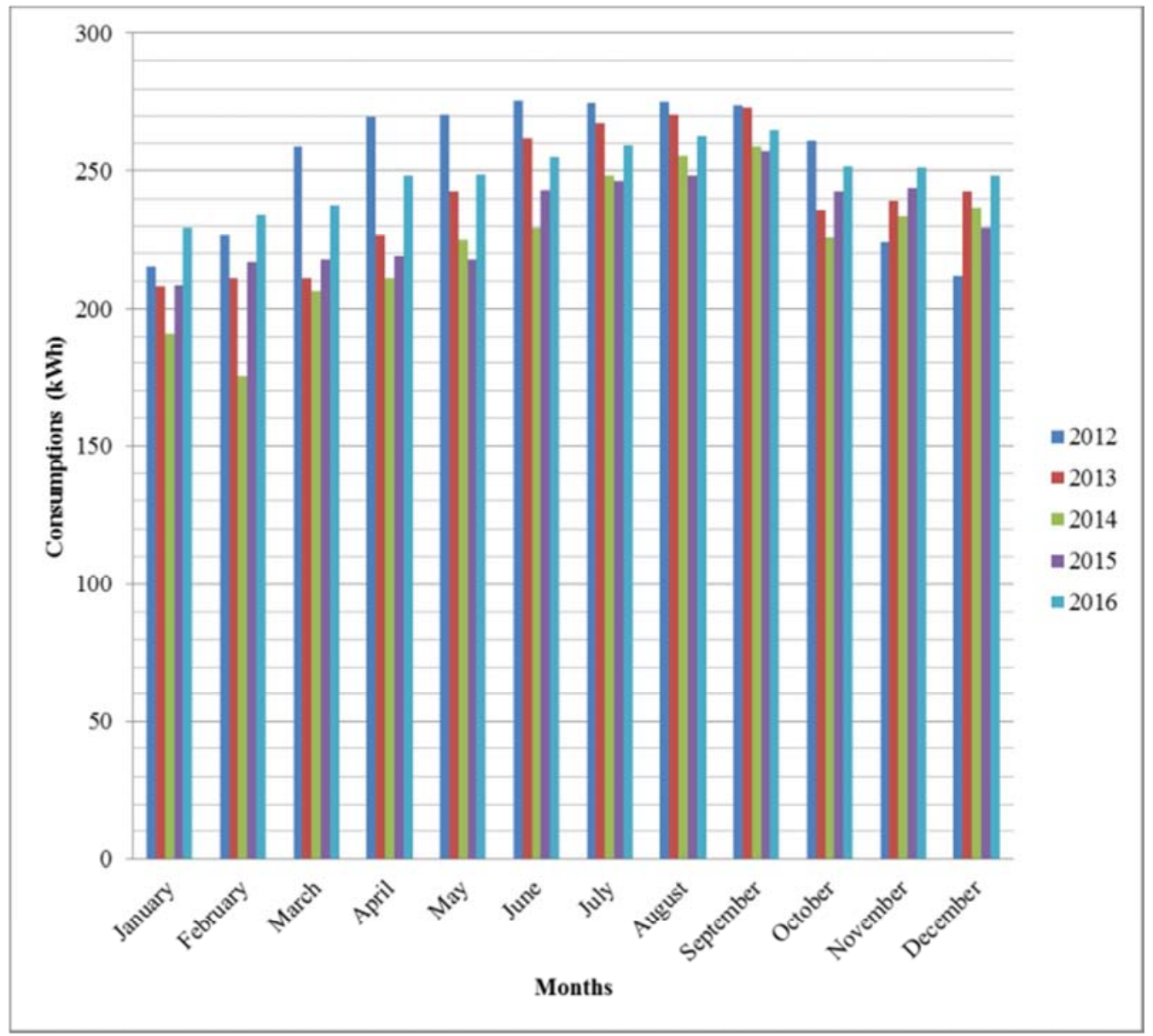

Figure 3. Monthly AGO Consumption Pattern (2012 - 2016). 


\subsubsection{Energy End Uses}

The case building energy model was simulated in eQUEST using input data from Appendix A. eQUEST provides outputs in two forms: A detailed simulation output file and a summary result/report (Figure C4). And also table B8 presents estimation of daily and monthly energy consumption per equipment (end users) for the company.

Figures 4 and 5 presents annual energy consumption by end use and annual peak demand by end use respectively.

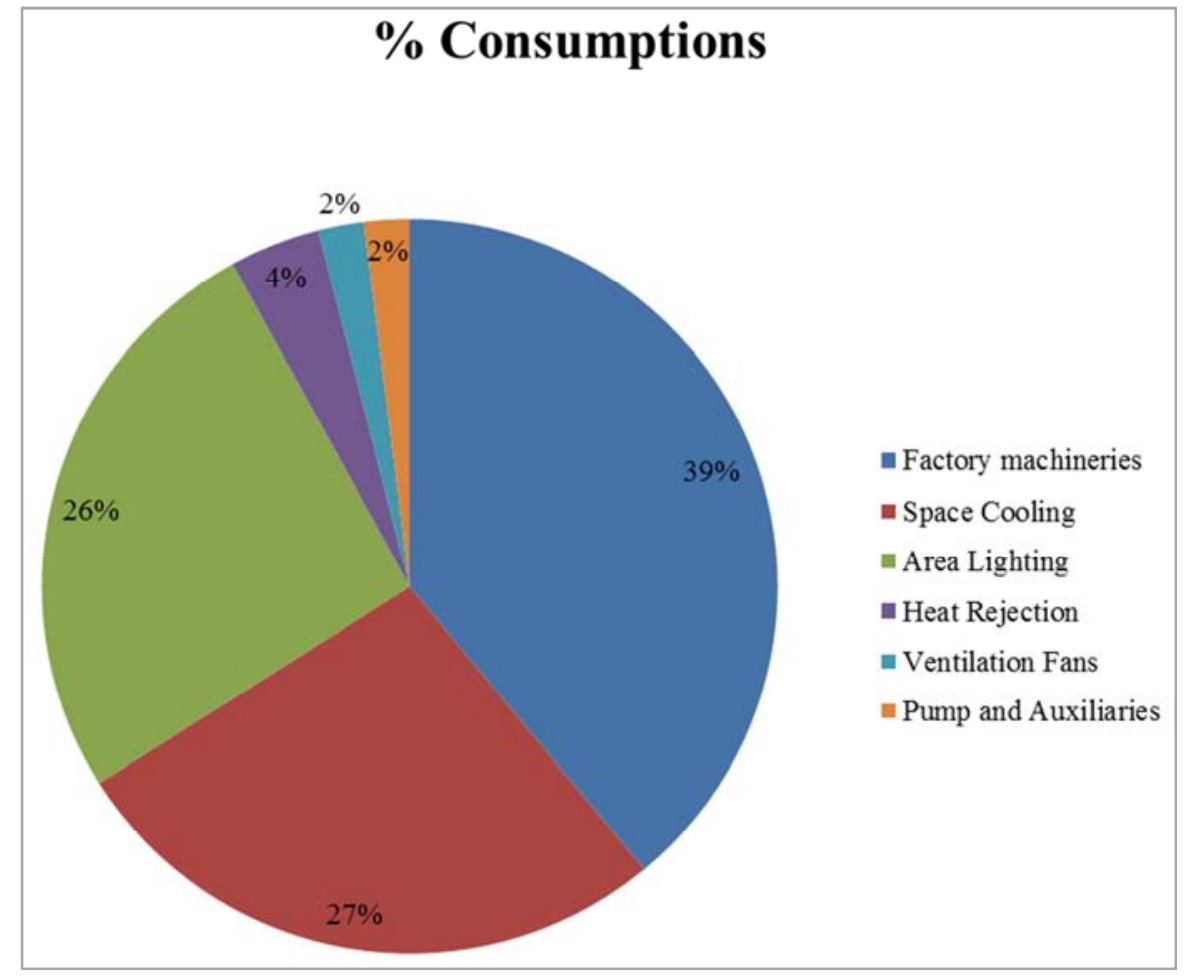

Figure 4. Annual Energy Consumption by End Use.

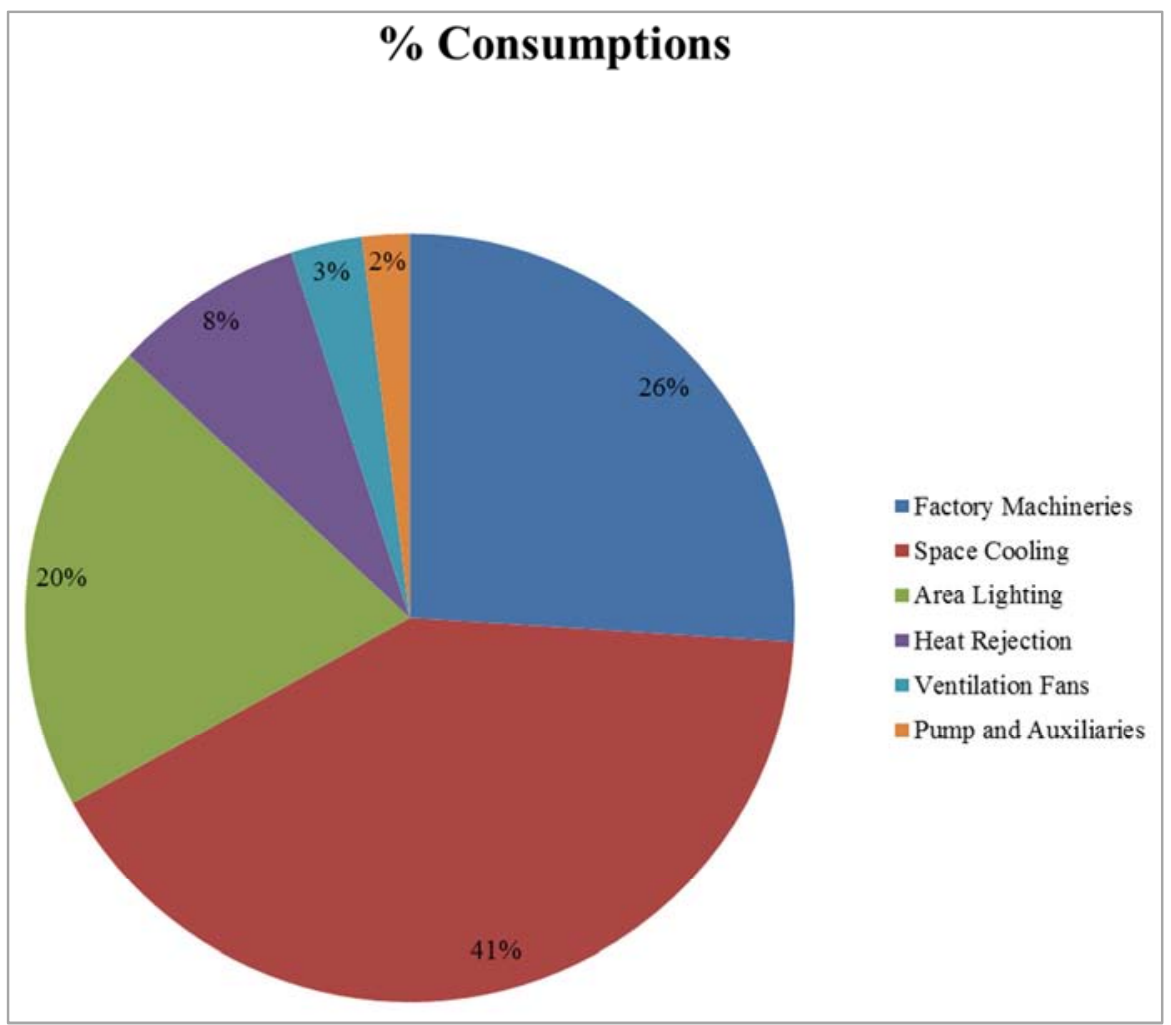

Figure 5. Annual Peak Demand by End Use. 


\subsubsection{Energy Performance Index}

Table B6 present the annual electricity consumption and energy used index of the tones of leather processed annually in appendix B.

\subsection{Discussion of the Results}

\subsubsection{Energy Carriers}

The consumption pattern showed distinct seasonal variation, indicating peak electricity demand during the hot, months from April to August resulting in significant Air conditioned requirement. The annual consumption of electricity and diesel of the company are $594803.61 \mathrm{kWh}$ and $14405.83 \mathrm{kWh}$ and percentage contribution of the energy carriers were $97.63 \%$ and $2.37 \%$ from National Grid and AGO respectively which show that the company depended on the energy from electricity.

\subsubsection{Energy End Uses}

The energy simulation results of the building has represented that the total monthly energy consumption by space cooling was $37633 \mathrm{kWh}$, ventilation fans $3070 \mathrm{kWh}$, factory machineries $53600 \mathrm{kWh}$, heat rejection is $5040 \mathrm{kWh}$, pump and auxiliary is $3000 \mathrm{kWh}$ and area lighting 35821 $\mathrm{kWh}$ respectively having a sum total of monthly energy consumption by the end users to be $138164 \mathrm{kWh}$. This represent an annual energy use in air-conditioning (space cooling) was $27 \%$, ventilation fan $2 \%$, factory machineries $39 \%$, heat rejection is $4 \%$, pump and auxiliary is $2 \%$ and area lighting $26 \%$ (figure 4 ). Also, the total monthly peak demand by space cooling was $22372.2 \mathrm{kWh}$, ventilation fan 1376 $\mathrm{kWh}$, factory machineries $14294 \mathrm{kWh}$ heat rejection is 4461 $\mathrm{kWh}$, pump and auxiliary is $1343 \mathrm{kWh}$ and area light 11023 $\mathrm{kWh}$ respectively having a sum total monthly peak demand by the end users to be $44969.2 \mathrm{kWh}$. This represent energy use in air-conditioning (space cooling) was $41 \%$, ventilation fan $3 \%, 26 \%$ factory machineries, heat rejection is $8 \%$, pump and auxiliary is $2 \%$ and $20 \%$ area light of the annual peak demand.

\subsubsection{Energy Conservation Measures}

Based on the evaluation/analysis of energy consumption pattern of the company, several energy conservation measures (ECMs) were analyzed and these were categorized into three groups of no cost, low cost and major cost investment measures.

\section{A. No Cost Measures}

These are measures that can be implemented through operational and behavioral means without the need for system or building alteration and, therefore do not require extra cost for their implementation [11]. For the company, the following measures were identifying for implementation. That is by applying schedule of equipment, set point temperature, infiltration and schedule of lighting.

Encourage Energy-Saving Behavior

A number of buildings are successfully using no-cost public awareness campaigns to reduce energy use. One popular and effective-energy awareness program is the Dorm Energy Challenge, in which residence halls compete against one another to make the largest energy reductions or simply to improve their own energy performance. This strategy can be adopted in this company in order to save energy.

B. Low Cost Measures

These are measures that can be implemented for building alterations or modifications through low cost investment.

i. Use of Energy Management Device Based on Image Processing

The lighting and power supply can be controlled by occupancy sensing. The feature of this device is that it controls the power supply of any place by sensing occupancy by any human. The distinguishing feature is that only human occupancy is detected. This device uses image processing and pattern recognition. This device is found to be an efficient method to implement energy management at a low cost. The Management should endeavor to install an automated occupancy sensor everyway in the company.

ii. Effective Metering system

Installation of pre-payment meters in the company, to monitor/curtail power wastages and thereby reduce energy cost on electric power.

\section{Conclusions and Recommendations}

\subsection{Conclusions}

The electricity energy consumption pattern of tannery company buildings was investigated and the following conclusions were drawn:

a) The consumption pattern showed distinct seasonal variation indicating peak electricity demand during the hot season from April to August resulting in significant Air conditioning requirement. Also, $2.37 \%$ of electricity consumed was contributed by the burning of AGO in the diesel power generators showing very less contribution over that of National grid $97.63 \%$.

b) The energy used index (Annual electricity Used per tones of leather) for five years 2012, 2013, 2014, 2015 and 2017 were 288.24 (kWh/tones of leather/Annum), 263.10 (kWh/tones of leather/Annum), 245.08 (kWh/tones of leather/Annum), $260.42(\mathrm{kWh} /$ tones of leather/Annum) and $259.56 \quad(\mathrm{kWh} /$ tones of leather/Annum) respectively. With an average value of $263.28 \mathrm{kWh} /$ tones of leather/Annum.

c) The company building was modeled and simulated using eQUEST-3.65 to investigate the building energy performance. Results shows that the sum total of the total monthly energy consumption by the end users is $138164 \mathrm{kWh}$ representing the total average value of the annual energy use in air-conditioning (space cooling) was $27 \%$, ventilation fan $2 \%$, factory machineries $39 \%$, heat rejection is $4 \%$, pump and auxiliary is $2 \%$ and area lighting $26 \%$. Also, the total monthly peak demand by space cooling was $22372.2 \mathrm{kWh}$, ventilation fan 1376 
$\mathrm{kWh}$, factory machineries $14294 \mathrm{kWh}$ heat rejection is $4461 \mathrm{kWh}$, pump and auxiliary is $1343 \mathrm{kWh}$ and area light $11023 \mathrm{kWh}$ respectively having a sum total monthly peak demand by the end users to be 44969.2 $\mathrm{kWh}$. This represent energy use in air-conditioning (space cooling) was $41 \%$, ventilation fan 3\%, 26\% factory machineries, heat rejection is $8 \%$, pump and auxiliary is $2 \%$ and $20 \%$ area light of the annual peak demand.

\subsection{Recommendations}

Based on the conclusion of this research work, the following recommendations are made for the existing building in company.

a) Creation of Energy Management Units in the company system to educate staff switch off the lights directly at the end of the day or when not in use. b) The company management should implement an automated lighting system, which helps in switching off street lights automatically during the day.

c) Use of high efficient equipment: High efficiency equipment reduces the energy needed to deliver a given level of energy services or produces more energy service per unit of energy. A careful observation shows that space cooling misc. equipment and area lighting were items which consumed the bulk of the energy supplied to the company, thus flagged areas for potential improvement of efficiency.

d) Reducing energy use for lighting: Energy use for lighting in company can be reduced by appropriate window design and glass to make maximum use of daylight while avoiding excessive solar gain. Energy efficient lighting systems (e.g. using task lighting) to avoid excessive background luminance levels.

\section{Appendix}

\section{Appendix A: General Information on Company Building}

Table A1. General Information on Company Building.

\begin{tabular}{ll}
\hline General Information & \\
\hline Project Name & Energy Audit \\
Building Type & Manufacturing Building \\
Location & Kano, Nigeria \\
Weather File & Kano, Nigeria \\
Analysis Year & 2019 \\
Building Envelope & \\
Building Shell Area & $92506 \mathrm{~m}^{2}$ \\
Number of Floors & 1 \\
Building Orientation & South \\
\hline
\end{tabular}

\section{Appendix B: Computed Results}

Table B1. Monthly Electricity Consumption ( $\mathrm{kWh}$ ).

\begin{tabular}{|c|c|c|c|c|c|c|}
\hline Months & 2012 & 2013 & 2014 & 2015 & 2016 & Average \\
\hline January & 10775.83 & 9015.556 & 10100 & 10334.72 & 10148.33 & 10074.89 \\
\hline February & 10455.83 & 9147.778 & 9891.111 & 10293.06 & 10267.78 & 10011.11 \\
\hline March & 9973.056 & 8955.556 & 10186.67 & 10328.33 & 10443.61 & 9977.444 \\
\hline April & 10290.83 & 9264.444 & 10162.78 & 10399.17 & 10550.28 & 10133.5 \\
\hline May & 10626.11 & 9815.556 & 10039.17 & 10515 & 10491.39 & 10297.44 \\
\hline June & 10152.22 & 9357.222 & 10352.5 & 10613.06 & 10596.11 & 10214.22 \\
\hline July & 10644.72 & 10035.56 & 10265.83 & 10701.67 & 10657.22 & 10461 \\
\hline August & 9431.944 & 9893.611 & 10525.28 & 10798.06 & 10908.33 & 10311.44 \\
\hline September & 10959.17 & 9346.944 & 10539.17 & 10810.83 & 10868.06 & 10504.83 \\
\hline October & 10270.83 & 9728.056 & 10192.5 & 10058.06 & 9796.944 & 10009.28 \\
\hline November & 10204.17 & 9314.444 & 10167.78 & 10011.94 & 9826.111 & 9904.889 \\
\hline December & 10160.56 & 9256.389 & 10118.89 & 10139.72 & 10033.61 & 9941.833 \\
\hline Total & 123945.3 & 113131.1 & 122541.7 & 125003.6 & 124587.8 & 121841.9 \\
\hline
\end{tabular}

Table B2. Total Electricity Energy Consumed by Energy carriers (National Grid and AGO).

\begin{tabular}{lllll}
\hline S/N & Years & National Grid & AGO & Total Electricity Energy \\
\hline 1 & 2012 & 120907.55 & 3037.778 & 2890 \\
2 & 2013 & 110241.1111 & 2696.944 & 113131.1111 \\
3 & 2014 & 119844.7222 & 2790.278 & 122541.6667 \\
4 & 2015 & 122213.3333 & 2990.833 & 125003.6111 \\
5 & 2016 & 121596.9444 & 14405.83 & 609209.4444 \\
\hline
\end{tabular}


Table B3. Annual Percentage contribution of each source

\begin{tabular}{llll}
\hline S/N & Years & \% by National Grid & \% by AGO \\
\hline 1 & 2012 & 97.54909761 & 2.450902 \\
2 & 2013 & 97.44544187 & 2.554558 \\
3 & 2014 & 97.79916128 & 2.200839 \\
4 & 2015 & 97.76784226 & 2.232158 \\
5 & 2016 & 97.59941674 & 2.400583 \\
\hline
\end{tabular}

Table B4. Monthly Average National Grid Consumption.

\begin{tabular}{llll}
\hline S/N & Years & Total annual electrical energy consumed $(\mathbf{k W h})$ & Monthly average electrical Energy consumed $(\mathbf{k W h})$ \\
\hline 1 & 2012 & 120907.55 & 10075.63 \\
2 & 2013 & 110241.1111 & 9186.759 \\
3 & 2014 & 119844.7222 & 9987.06 \\
4 & 2015 & 122213.3333 & 10184.44 \\
5 & 2016 & 121596.9444 & 10133.08 \\
& AVERAGE & 118960.7222 & 9913.394 \\
\hline
\end{tabular}

Table B5. Annual and Monthly Average Diesel Consumed.

\begin{tabular}{llllll}
\hline \multirow{2}{*}{ S/N } & \multirow{2}{*}{ Years } & \multicolumn{2}{l}{ Total Annual Diesel Consumed } & \multicolumn{2}{l}{ Monthly Average Diesel Consumed } \\
\cline { 3 - 6 } & & Litres & $\mathbf{k W h}$ & Litres & $\mathbf{k W h}$ \\
\hline 1 & 2012 & 283.3160622 & 3037.778 & 23.60967185 & 253.1481 \\
2 & 2013 & 269.5336788 & 2890 & 22.4611399 & 240.8333 \\
3 & 2014 & 251.5284974 & 2696.944 & 20.96070812 & 224.7454 \\
4 & 2015 & 260.2331606 & 2790.278 & 21.68609672 & 232.5231 \\
5 & 2016 & 278.9378238 & 2990.833 & 23.24481865 & 249.2361 \\
\hline
\end{tabular}

Table B6. Energy Use Index for Company.

\begin{tabular}{llll}
\hline Year & Tones of leather & Electricity consumption (kWh/Annum) & Energy use index (kWh/tones of leather/Annum) \\
\hline 2012 & 174 & 123945 & 712.33 \\
2013 & 162 & 113131 & 698.34 \\
2014 & 170 & 122542 & 720.84 \\
2015 & 171 & 125004 & 731.02 \\
2016 & 172 & 124588 & 724.35 \\
\hline
\end{tabular}

Table B7. Monthly Diesel Consumption ( $k W h)$.

\begin{tabular}{llllllll}
\hline Months & $\mathbf{2 0 1 2}$ & $\mathbf{2 0 1 3}$ & $\mathbf{2 0 1 4}$ & $\mathbf{2 0 1 5}$ & $\mathbf{2 0 1 6}$ & Total & Average Total \\
\hline January & 215 & 207.7778 & 191.1111 & 208.3333 & 229.7222 & 1051.944 & 210.3889 \\
February & 226.6667 & 210.8333 & 175.2778 & 216.9444 & 234.1667 & 1063.889 & 212.7778 \\
March & 258.6111 & 210.8333 & 206.3889 & 217.5 & 237.5 & 1130.833 & 226.1667 \\
April & 270 & 226.6667 & 210.8333 & 218.8889 & 248.0556 & 1174.444 & 234.8889 \\
May & 270.5556 & 242.7778 & 224.7222 & 217.5 & 248.6111 & 1204.167 & 240.8333 \\
June & 275.8333 & 261.9444 & 229.7222 & 243.0556 & 255 & 1265.556 & 253.1111 \\
July & 275 & 267.5 & 248.3333 & 246.3889 & 259.4444 & 1296.667 & 259.3333 \\
August & 275.5556 & 270.5556 & 255.2778 & 248.0556 & 262.7778 & 1312.222 & 262.4444 \\
September & 273.8889 & 273.0556 & 258.8889 & 257.2222 & 264.7222 & 1327.778 & 265.5556 \\
October & 261.1111 & 235.8333 & 225.5556 & 242.5 & 251.6667 & 1216.667 & 243.3333 \\
November & 223.8889 & 239.4444 & 233.8889 & 244.1667 & 251.1111 & 1192.5 & 238.5 \\
December & 211.6667 & 242.7778 & 236.9444 & 229.7222 & 248.0556 & 1169.167 & 233.8333 \\
Total & 3037.778 & 2890 & 2696.944 & 2790.278 & 2990.833 & 14405.83 & 2881.167 \\
\hline
\end{tabular}

Table B8. Estimation of Daily and Monthly Energy Consumption per Equipment (End Users) for the Company.

\begin{tabular}{llllllll}
\hline S/N & Equipment & Quantity & $\begin{array}{l}\text { Power } \\
\text { Rating (hp) }\end{array}$ & $\begin{array}{l}\text { Working } \\
\text { hours/day }\end{array}$ & $\begin{array}{l}\text { Power } \\
\text { Rating (kW) }\end{array}$ & $\begin{array}{l}\text { Power Consumption } \\
\text { per day (kWh) }\end{array}$ & $\begin{array}{l}\text { Power Consumption } \\
\text { per Month (kWh) }\end{array}$ \\
\hline 1 & Air Conditioning & 10 & 20 & 8 & 14.9142 & 119.313945 & 2386.2789 \\
2 & Office Lights & 30 & 1.2 & 9 & 0.89485 & 8.05369128 & 161.073826 \\
3 & Factory Lights & 60 & 2.4 & 9 & 1.78970 & 16.1073826 & 322.147651 \\
4 & Refrigerator & 2 & 0.26 & 5 & 0.19388 & 0.9694258 & 19.388516 \\
5 & Welding Machine & 1 & 6.7 & 1 & 4.99627 & 4.99627144 & 99.9254288 \\
6 & Grinding Machine & 1 & 3.2 & 1 & 2.38627 & 2.3862789 & 47.7255779 \\
7 & Photostat Machine & 2 & 1.6 & 0.5 & 1.19313 & 0.59656972 & 11.9313945 \\
\hline
\end{tabular}




\begin{tabular}{llllllll}
\hline S/N & Equipment & Quantity & $\begin{array}{l}\text { Power } \\
\text { Rating (hp) }\end{array}$ & $\begin{array}{l}\text { Working } \\
\text { hours/day }\end{array}$ & $\begin{array}{l}\text { Power } \\
\text { Rating (kW) }\end{array}$ & $\begin{array}{l}\text { Power Consumption } \\
\text { per day (kWh) }\end{array}$ & $\begin{array}{l}\text { Power Consumption } \\
\text { per Month (kWh) }\end{array}$ \\
\hline 8 & Ceiling Fan & 30 & 2.2 & 8 & 1.64056 & 13.1245339 & 262.490679 \\
9 & Television & 2 & 0.05 & 6 & 0.03728 & 0.22371365 & 4.47427293 \\
10 & Receiver & 2 & 0.05 & 6 & 0.03728 & 0.22371365 & 4.47427293 \\
11 & Printer & 3 & 1.89 & 1 & 1.40939 & 1.40939597 & 28.1879195 \\
12 & Pumps & 3 & 33.5 & 9 & 24.9813 & 224.832215 & 4496.6443 \\
13 & Boiler & 2 & 8.5 & 8 & 6.33855 & 50.7084265 & 1014.16853 \\
14 & Measuring Machine & 1 & 2 & 2 & 1.49142 & 2.98284862 & 59.6569724 \\
15 & Keaser Compressor & 1 & 10 & 4 & 7.45712 & 29.8284862 & 596.569724 \\
16 & Rotor Press Machine & 2 & 27 & 9 & 20.1342 & 181.208054 & 3624.16107 \\
17 & Dryers & 2 & 7 & 9 & 5.21998 & 46.9798658 & 939.597315 \\
18 & Water Conditioning Machine & 1 & 2 & 9 & 1.49142 & 13.4228188 & 268.456376 \\
19 & Molissa & 2 & 12 & 9 & 8.94854 & 80.5369128 & 1610.73826 \\
20 & Toggling & 3 & 22.5 & 9 & 16.7785 & 151.006711 & 3020.13423 \\
21 & Buffing & 4 & 38 & 6 & 28.3370 & 170.022371 & 3400.44743 \\
22 & De-Dusting & 2 & 11 & 6 & 8.20283 & 49.2170022 & 984.340045 \\
23 & Setting-out Machine & 4 & 52.5 & 6 & 39.1498 & 234.899329 & 4697.98658 \\
24 & Drums & 7 & 77 & 9 & 57.4198 & 516.778523 & 10335.5705 \\
25 & Fleshing Machine & 6 & 66 & 9 & 49.2170 & 442.95302 & 8859.0604 \\
26 & Paddle & 8 & 40 & 6 & 29.8284 & 178.970917 & 3579.41834 \\
27 & Desktop Computer & 3 & 1 & 0.5 & 0.74571 & 0.37285608 & 7.45712155 \\
28 & Laptop & 7 & 1 & 0.5 & 0.74571 & 0.37285608 & 7.45712155 \\
29 & Dust Extractors & 10 & 5 & 4 & 3.72856 & 14.9142431 & 298.284862 \\
30 & Rotor Stacking Machine & 2 & 19 & 9 & 14.1685 & 127.516779 & 2550.33557 \\
& & & & & Total & 2684.92916 & 53698.5831 \\
\hline
\end{tabular}

Table B9. Average Monthly National Grid and AGO Consumptions.

\begin{tabular}{|c|c|c|}
\hline \multirow{2}{*}{ Months } & Average Monthly National Grid & Average Monthly AGO \\
\hline & $\mathrm{kWh}$ & Litres \\
\hline January & 9864.5 & 19.62176 \\
\hline February & 9798.333 & 19.84456 \\
\hline March & 9751.278 & 21.09326 \\
\hline April & 9898.611 & 21.90674 \\
\hline May & 10056.61 & 22.46114 \\
\hline June & 9961.111 & 23.60622 \\
\hline July & 10201.67 & 24.18653 \\
\hline August & 10049 & 24.47668 \\
\hline September & 10239.28 & 24.76684 \\
\hline October & 9765.944 & 22.6943 \\
\hline November & 9666.389 & 22.24352 \\
\hline December & 9708 & 21.80829 \\
\hline
\end{tabular}

\section{Appendix C: Screenshots of the Simulation Using eQUEST}

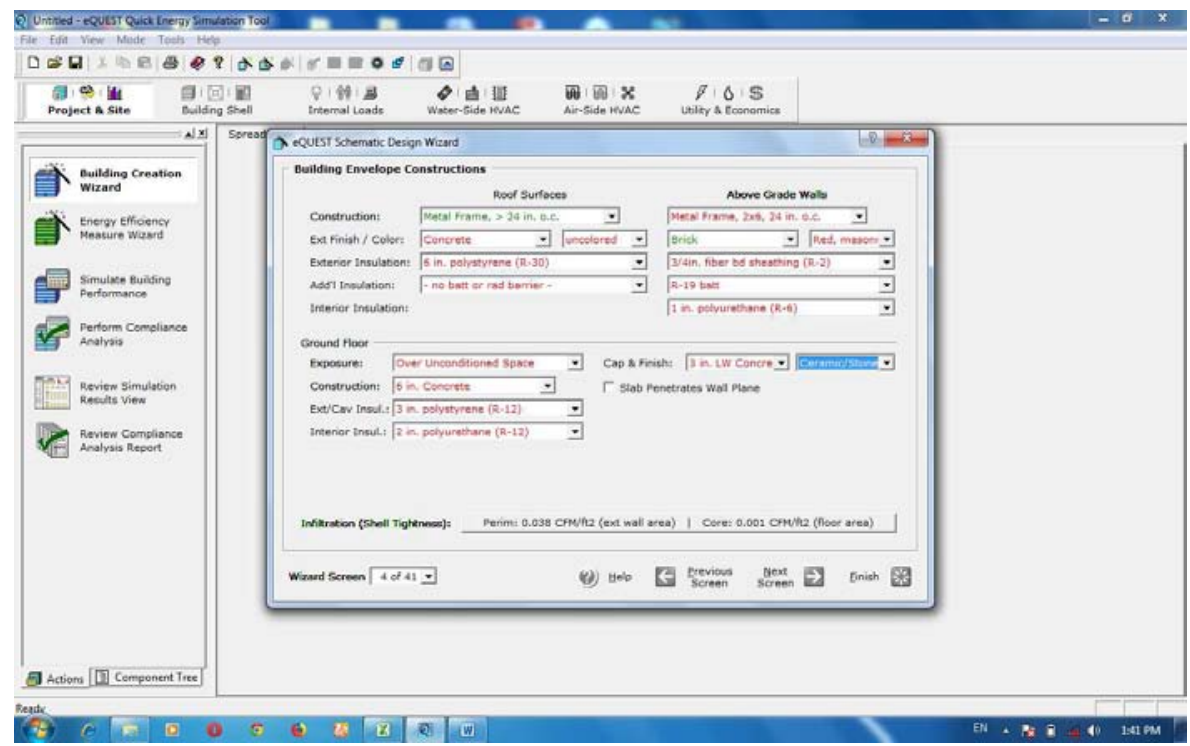

Figure C1. A screenshot of the eQUEST wizard screen for building material and envelope details. 

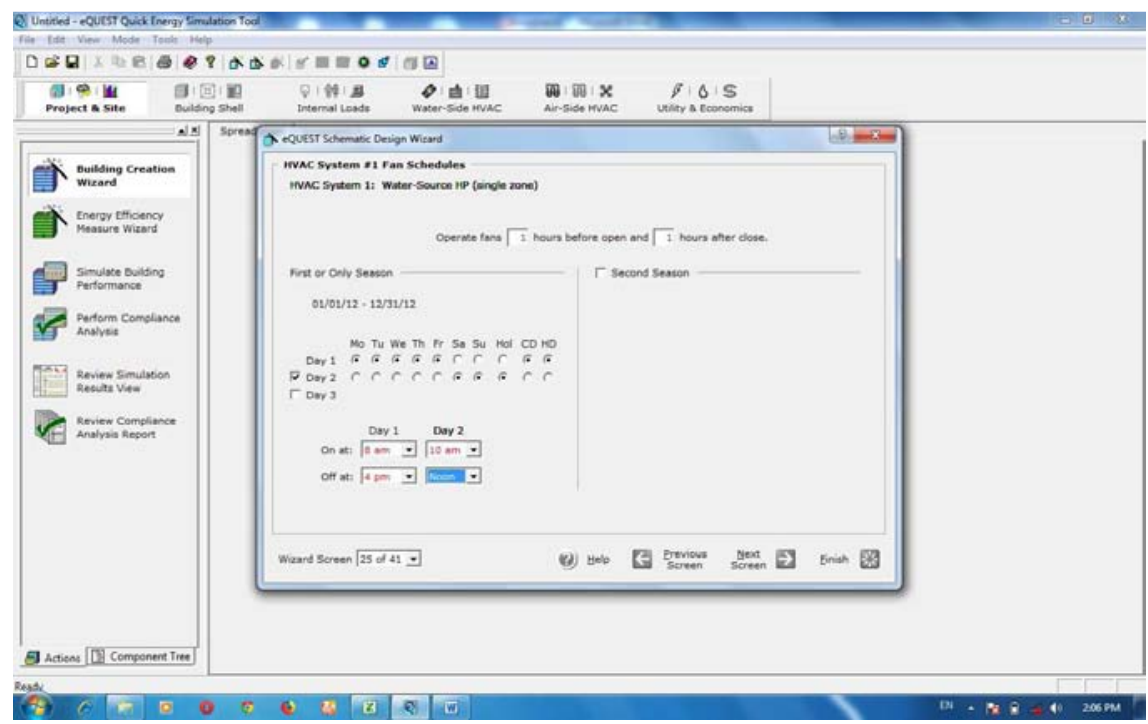

Figure C2. A screenshot of the eQUEST wizard screen for HVAC System.
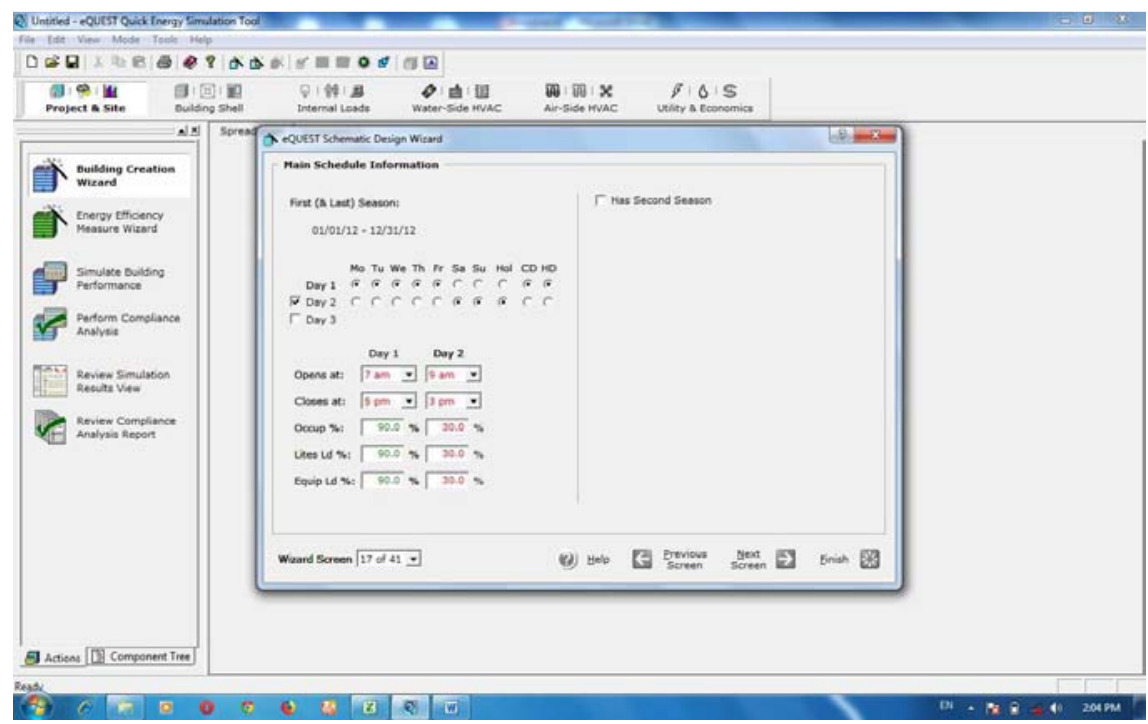

Figure C3. A screenshot of the eQUEST wizard screen for building schedules.

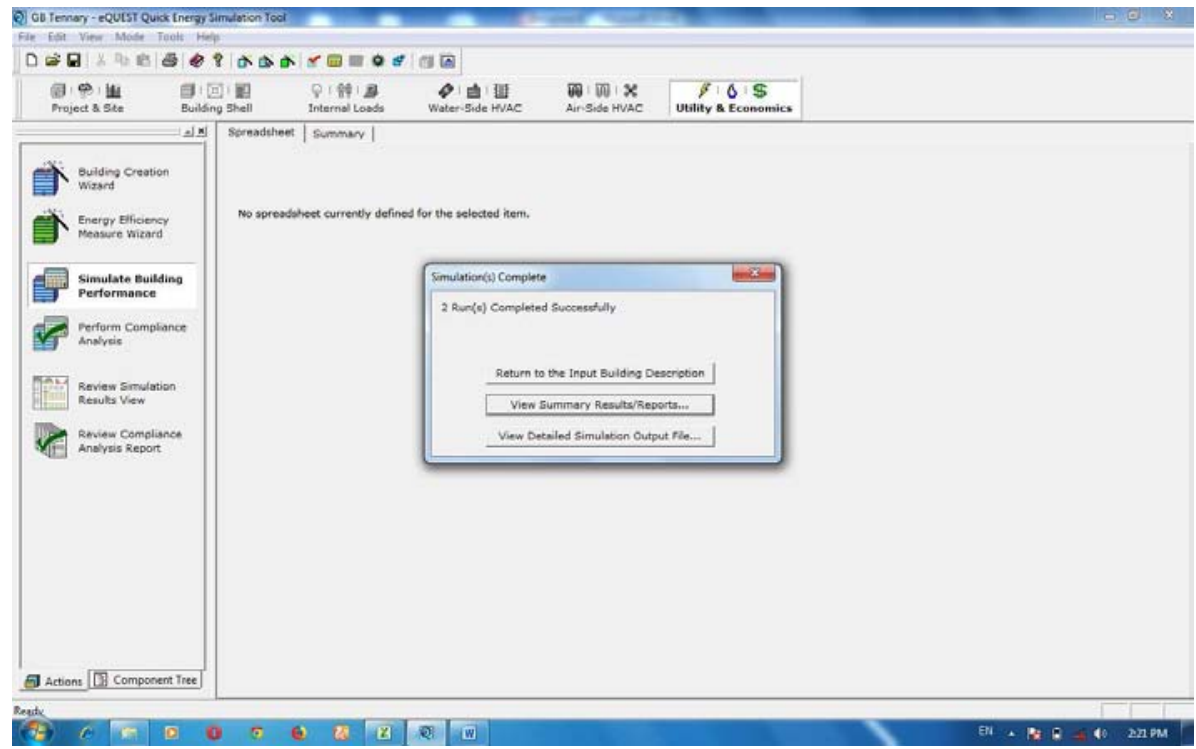

Figure C4. Simulation Output Window in eQUEST. 


\section{References}

[1] Jamilu, Y. M.; Adamu, A. A.; Mika'il, A. A.; Yerima Y. A. (2018). Energy Audit and Efficiency of a Complex Building: A Comprehensive Review. Engineering Science. 3 (4): 36-41. doi: $10.11648 /$ j.es.20180304.11.

[2] Habib, M. A.; Said, S. A. M.; Igbo, M. O.; El-Mahallawy, F. M.; Mahdi, E. A. (1999). Energy Conservation and Early Failure Prediction in Boilers and Industrial Furnaces. Symposium in management of energy consumption in industry, chamber of commerce, kingdom of Saudi Arabia.

[3] Galadima, U. (2001). Analysis of Electricity Energy Consumption for Effective Utilization in a Government Owned Housing Unit in Zamfara State. Unpublished M. Eng. Thesis, Bayero University, Kano.

[4] Tukur, U. (2013). Study of Electrical Energy Utilization in Katsina General Hospital. Unpublished PGDME Project, Bayero University, Kano.

[5] Lohani S. P. (2010). Energy and exergy analysis of fossil plant and heat pump building heating system at two different deadstate temperatures, Energy 35 (8): 3323-3331.

[6] Kondo, K. (2009). Energy and exergy utilization efficiencies in the Japanese residential/commercial sectors. Energy Policy, 37: $3475-3483$.

[7] James, S. (2006). Green building and sustainability. Building Science Digest, 5: 1-11.

[8] Almohoud, M. (2001). Computer-aided building energy analysis techniques. Building and Environment, 36 (4): 421-433.

[9] Zhu, Y. (2006). Applying computer-based simulation to energy auditing: a case study. Energy and Buildings, 38 (5): 421-428.

[10] eQUEST. (2008). eQUEST-The quick energy simulation tool, an overview. Retrieved from http://www.doe2.com/download/equest/eQUESTv3Overview.pdf

[11] Lam, J. C.; Chan, R. Y. C.; Tsang C. L.; Li D. H. W. (2004). Electricity use characteristics of purpose, built office building in subtropical dimates. Energy conversion and management Energy-int. J; 45: 829-844. 